\title{
Effect of Alternate Wetting and Drying on some Properties of High Strength Concrete in Tropical Coastal Environments
}

\author{
Durojaye O. M. ${ }^{1}$ and Ogirigbo O. R. ${ }^{2, *}$ \\ ${ }^{1,2}$ Department of Civil Engineering, Faculty of Engineering, University of Benin, Benin City, Edo State, Nigeria \\ Corresponding Author: *okiemute.ogirigbo@uniben.edu
}

https://doi.org/10.36263/nijest.2020.01.0189

\begin{abstract}
Concrete is one of the most used construction materials in the world, due to its good durability and fire resistance properties, versatility in forming various shapes, abundance of raw materials and low manufacturing and maintenance costs. High strength concrete, which is a type of concrete, finds its application in construction of high rise buildings, bridges, highways, etc. Its physical properties are greatly affected by the method of curing and the environment in which it is placed. This study investigated the effect on the compressive strength and some transport properties of high strength concrete subjected to alternate wetting and drying exposure, which may be due to intermittent rains, or rise and fall in tides of the sea, an exposure type that is commonly experienced in coastal areas. High strength concrete samples were prepared and subjected to two different curing regimes, one in which the concrete samples were cured continuously under water, and the other in which the concrete samples were subjected to 12-hr curing under water followed by 12-hr curing under ambient air. Various tests such as ultrasonic pulse velocity (UPV), compressive strength, water and chloride ingress tests were conducted on the cured concrete samples. The results obtained from the tests conducted, generally showed that the strength and transport properties of the high strength concrete was greatly affected by the alternate wetting and drying curing method. The effect was seen to be more adverse at the later ages than at the early ages.
\end{abstract}

Keywords: Compressive strength, Cyclic curing, Marine environment, Water ingress, Chloride ingress, Niger Delta

\subsection{Introduction}

High strength concrete is mostly used for high rise structures, bridges, etc. It is often sticky and very difficult to be handled and placed. This is usually the condition even if plasticizers are used. This condition is mainly due to the high cement content in it. Due to the superior mechanical properties and the significant economic savings offered by high strength concrete, the use of it has accelerated. For instance, the use of high strength concrete can shorten turnover times of casting beds and speed up construction time. It can also allow for the use of more slender members, thus reducing the dead load of sections (French and Mokhtarzadeh, 1993).

Concrete strength is determined by the force required to crush it and this strength can be affected by cyclic changes in moisture and temperature. Hence, the environment in which concrete is placed after mixing is of great importance (Kamran, 2015). Thus, if high strength concrete is allowed to dry prematurely, it can experience unequal tensile stresses that in an imperfectly hardened state cannot be resisted. The strength of concrete improves with proper curing after it is cast. Generally, it is good practice to maintain a temperature between about $5^{\circ} \mathrm{C}$ and $20^{\circ} \mathrm{C}$ during the first half day after placing the concrete. During this initial period, a much higher temperature might retard the later development in strength, while a much lower temperature (such as would cause the fresh concrete to freeze) might permanently impair the strength. After this initial period, the strength development increases with the maturity of the concrete i.e. the product of age and temperature (Neville, 1996). 
Temperature variation can cause changes in concrete volume. Increasing the temperature can result to an increase in the volume of the concrete. On the other hand, when the temperature falls, the concrete contracts, and this is typically what happens in coastal regions. If the concrete is unrestricted then the volume changes will not have too many consequences. However, the concrete is always restrained by foundations, reinforcement or connecting members, and as a result of this, the change in volume will produce significant stress in the concrete that may result in the formation of cracks (Sidney, 1979).

In coastal regions where the concrete is close to the sea, it is bound to experience alternate wetting and drying as a result of the rise and fall in tides of the sea or ocean. This alternate wetting and drying can have adverse effect on the properties of the concrete. These effects have been studied by several researchers e.g. Jaya et al., 2014; Garzon-Roca et al., 2015; Sobhan et al., 2015; Tang et al., 2018. However, in all these studies, very little attention was given to coastal regions in tropical environments. This is significant, as coastal regions in tropical environments like Nigeria are well known for their peculiar temperature ranges. For example, in Lagos, Nigeria, the temperature ranges from $\sim 23^{\circ} \mathrm{C}$ to $\sim 33^{\circ} \mathrm{C}$. Hence, there is need to understand how alternate wetting and drying exposure conditions will impact on the properties of concrete in such regions.

In this study, the strength and some transport properties of high strength concrete cured under alternate wetting and drying conditions is compared with that cured under ideal conditions (i.e. continuously under water). The outcome of this study is significant as it will give more understanding about the performance of concrete structures in the coastal regions of Nigeria - a region that has a coastline of over $1,000 \mathrm{~km}$ and houses many marine concrete structures such as harbours, jetties, quays, seaports and breakwaters.

\subsection{Methodology}

\subsection{Materials}

\subsubsection{Cement}

The cement used for the study was procured from a local vendor. It had a strength grade of 42.5 and conformed to the specifications given in BS EN 196-1:2016. The physical and chemical properties of the cement are shown in Tables 1 and 2 respectively.

\subsubsection{Aggregates}

The fine aggregate used for the study was obtained from a quarry site at Ugbioko community at Edo State, Nigeria. Sieve analysis conducted on it placed it at Zone II, with a maximum particle size of $4.75 \mathrm{~mm}$. Grading of the fine aggregates conformed to BS EN 12620:2002+A1. The coarse aggregate used was crushed granite, with particle size ranging from $14-20 \mathrm{~mm}$, and a specific gravity of 2.71 . The properties of the fine and coarse aggregates used for the study are shown in Table 3.

Table 1: Physical properties of the cement

\begin{tabular}{lc}
\hline Property & Value \\
\hline Average fineness (\%) & 7 \\
Normal consistency (mm) & 33 \\
Setting time & \\
Initial (minutes) & 85 \\
Final (minutes) & 240 \\
\hline
\end{tabular}

Table 2: Chemical properties of the cement

\begin{tabular}{lc}
\hline Property & $\%$ \\
\hline Lime $(\mathrm{CaO})$ & 60.87 \\
Alumina $\left(\mathrm{Al}_{2} \mathrm{O}_{3}\right)$ & 5.36 \\
Soluble silica $\left(\mathrm{SiO}_{2}\right)$ & 20.55 \\
Iron oxide $\left(\mathrm{Fe}_{2} \mathrm{O}_{3}\right)$ & 4.00 \\
Chloride $\left(\mathrm{Cl}_{2}\right)$ & $<0.1$ \\
Magnesia $(\mathrm{MgO})$ & 0.74 \\
Sulfuric Anhydride $\left(\mathrm{SO}_{3}\right)$ & 1.83 \\
Insoluble residue & 2.93 \\
$\mathrm{Al}_{2} \mathrm{O}_{3} / \mathrm{Fe}_{2} \mathrm{O}_{3}$ & 1.34 \\
\hline
\end{tabular}


Table 3: Properties of the aggregates

\begin{tabular}{lll}
\hline Property & Fine aggregate & Coarse aggregate \\
\hline Specific gravity & 2.60 & 2.71 \\
Density & 1.52 & 1.61 \\
Zone & II & N/A \\
Crushed/uncrushed & N/A & Crushed \\
Maximum size of aggregate & $4.75 \mathrm{~mm}$ & $20 \mathrm{~mm}$ \\
\hline
\end{tabular}

\subsubsection{Water}

Potable water as obtained from the University's main water supply was used for mixing the concrete. The water was free from all forms of impurities and organic matter.

\subsubsection{Salt solution}

The salt solution used for the chloride ingress studies was prepared in the laboratory by mixing $30 \mathrm{~g}$ of salt (sodium chloride) in 1 litre of water. This has similar chloride concentration as that of Atlantic seawater, which is about 18g/l (Hewlett, 2004).

\subsection{Concrete mix design and sample preparation}

The concrete mix used for the study was that for a high strength concrete (with 28-day strength $>40$ $\mathrm{MPa}$ ). The mix ratios of the various constituents are shown in Table 4.

Table 4: Mix proportions of the starting materials

\begin{tabular}{llllll}
\hline $\begin{array}{l}\text { Water/cement } \\
\text { ratio }(\mathrm{w} / \mathrm{c})\end{array}$ & $\begin{array}{l}\text { Cement } \\
\left(\mathrm{kg} / \mathrm{m}^{3}\right)\end{array}$ & $\begin{array}{l}\text { Fine } \\
\left(\mathrm{kg} / \mathrm{m}^{3}\right)\end{array}$ & Aggregates & $\begin{array}{l}\text { Coarse } \\
\left(\mathrm{kg} / \mathrm{m}^{3}\right)\end{array}$ & Aggregates \\
\hline 0.51 & 461 & 597 & & 1107 & \\
\hline
\end{tabular}

The various constituents (cement, water and aggregates) were weighed separately and placed in the concrete mixer. After mixing, the concrete was placed into $100 \mathrm{~mm}$ cube moulds. The moulds were covered with thin polythene sheets and left to cure in the laboratory for at least 24 hrs, after which the cubes were demoulded and taken to the various curing environments. A total of 36 concrete cubes were used in the study.

\subsection{Details of curing conditions}

Two different curing methods were selected for this study. They are described as follows:

1. Continuous Wet Curing (WC): Immediately after demoulding, samples to be cured under this method were taken and placed under water in curing tanks for a period up to 28 days at a temperature and relative humidity of $25^{\circ} \mathrm{C}$ and $99 \%$ respectively.

2. Alternate Wetting and Drying $(\mathrm{W}+\mathrm{D})$ : After demoulding, these samples were subjected to a cyclic wet-dry curing condition. This involved placing the concrete samples under water for a period of $12 \mathrm{hrs}$ (at a temperature and relative humidity of $25^{\circ} \mathrm{C}$ and $99 \%$ respectively), followed by allowing them to dry under air in the laboratory for $12 \mathrm{hrs}$ (at a temperature and relative humidity of $\sim 35^{\circ} \mathrm{C}$ and $\sim 65 \%$ respectively). This represents the typical environmental conditions of the tropical coastal areas of Nigeria. This wetting and drying cycle was repeated daily for 28 days.

\subsection{Test methods}

Ultrasonic pulse velocity (UPV) test was conducted on triplicate samples of the concrete at ages of 3 , 7, 14 and 28 days. UPV is a non-destructive test that enables the strength and quality of the concrete to be assessed. The test was conducted by passing a pulse of ultrasonic through the concrete to be tested and measuring the time taken by the pulse to pass through the concrete. The pulse velocity was obtained using the expression below:

$$
\begin{array}{ll}
V=\frac{W}{t} & \\
\text { where: } & \\
V & \text { pulse velocity in } \mathrm{m} / \mathrm{s} \\
W & \text { width of the concrete cube in } \mathrm{m} \\
t & \text { time taken for the pulse to pass through the concrete cube in secs }
\end{array}
$$


Compressive strength was determined on triplicate samples using a cube crusher, at specific ages of 3 , 7,14 and 28 days, to study the effect of the alternate wetting and drying curing condition on the early and later strength of the concrete. A total of 24 concrete cubes were used for the compressive strength tests; 12 of these were cured under water while the other 12 were subjected to alternate wetting and drying method of curing. At the test age, the concrete cubes were brought out from their respective curing environment, surface dried (as applicable), and weighed before testing. The compressive strength (in $\mathrm{MPa}$ ) was taken as the average failure load (in $\mathrm{kN}$ ) divided by the cross sectional area of the concrete cube (in $\mathrm{mm}^{2}$ ), as shown in the expression below:

$P=\frac{F}{A}$

where:

$P \quad$ compressive strength in $\mathrm{MPa}$

$F \quad$ failure load in $\mathrm{kN}$

A cross sectional area of concrete cube in $\mathrm{mm}^{2}$

Water ingress tests were carried out according to BS1881-122:2011, on triplicate concrete cubes cured under the two curing conditions adopted in the study. After 28 days of curing under the various curing regimes, the concrete samples were immersed completely in water for 24 hrs. The mass of the samples were recorded before and after immersion in the water, and the water absorbed $\left(W_{a}\right)$ as a percentage was obtained using the expression below:

$$
\begin{array}{cl}
W_{a}=\frac{\left(M_{t}-M_{d}\right)}{M_{d}} & \\
\text { where: } & \\
M_{d} & \text { dry mass of the sample in grams } \\
M_{t} & \text { mass of the sample after time } t, \text { in grams } \\
W_{a} & \text { water absorbed in } \%
\end{array}
$$

The depth of chloride ion penetration was determined using the silver nitrate colouration technique as used by (Güneyisi and Mermerdaş, 2007; Ogirigbo and Inerhunwa, 2017). The concrete cubes after curing in the various curing regimes, were exposed to the salt solution for a period of 56 days. At the end of the exposure period, the samples were withdrawn and split in half. Thereafter, the surfaces of the freshly split samples were sprayed with a $0.1 \mathrm{M}$ silver nitrate $\left(\mathrm{AgNO}_{3}\right)$ solution. The presence of free chlorides was indicated by the formation of a white precipitate of silver chloride, while in the absence of free chlorides the reaction between silver nitrate and portlandite results in a brown colouration (as shown in Figure 1). The depth of free chloride penetration was then obtained by taking linear measurements from the edge of the specimen up to the colour change boundary. Six to eight measurements were taken per sample, and the average was taken as the depth of free chloride penetration. 
(a)

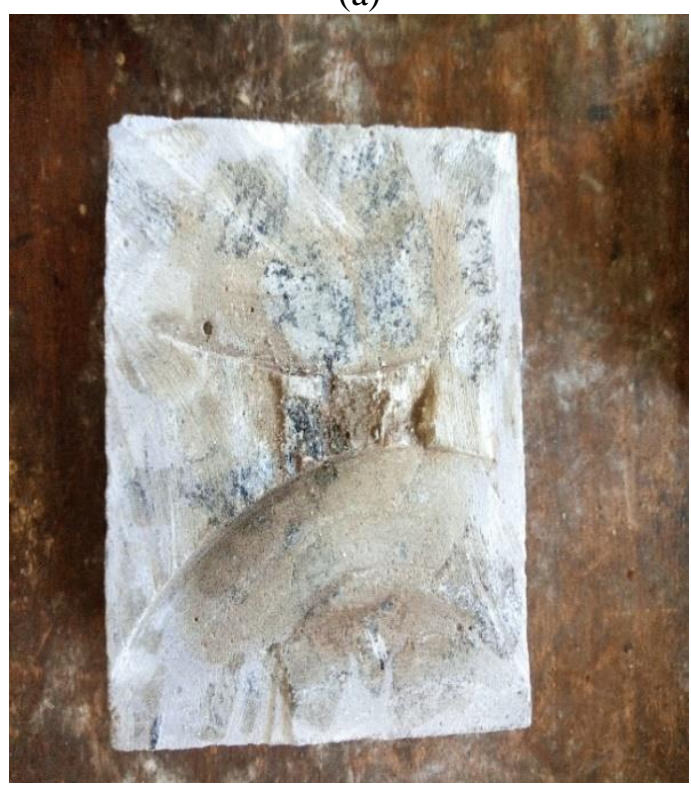

(b)

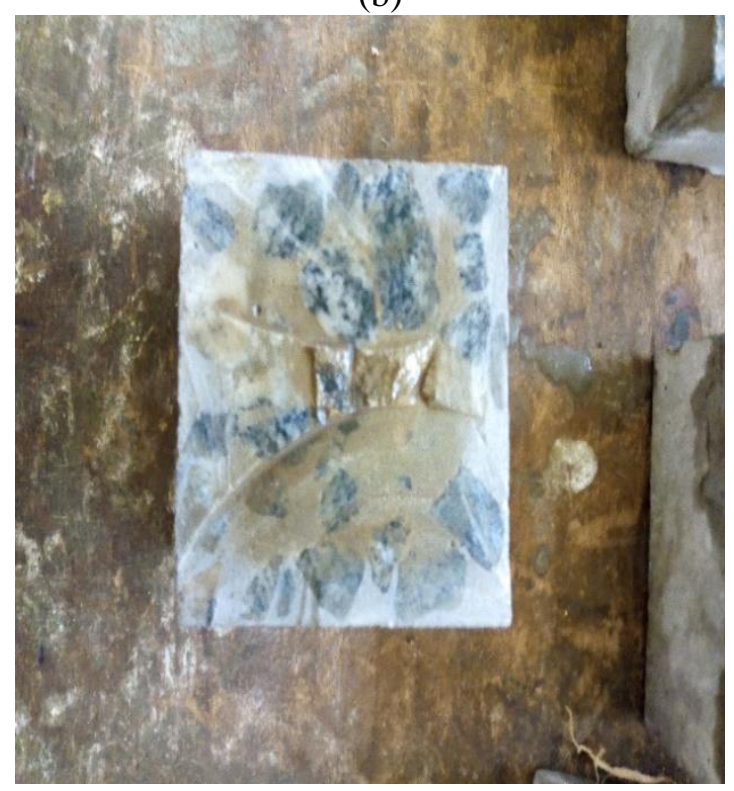

Figure 1: (a) before the application of silver nitrate (b) after the application of silver nitrate

\subsection{Results and Discussion}

\subsection{Ultrasonic pulse velocity}

Figure 2 shows the pulse velocity obtained for concrete cubes at the ages of 3, 7, 14 and 28 days. Irrespective of the curing method, the pulse velocity was seen to increase with the age of the samples, thus indicating that the strength and quality of the concrete samples increased with age. Comparing both curing methods, it can be seen that the concrete samples that were cured continuously under water had higher pulse velocities than those that were subjected to the alternate wetting and drying curing method. Higher velocities indicate good quality and continuity of the material, while slower velocities may indicate concrete with many cracks or voids. Thus, the concrete samples subjected to continuously curing under water are of a higher quality.

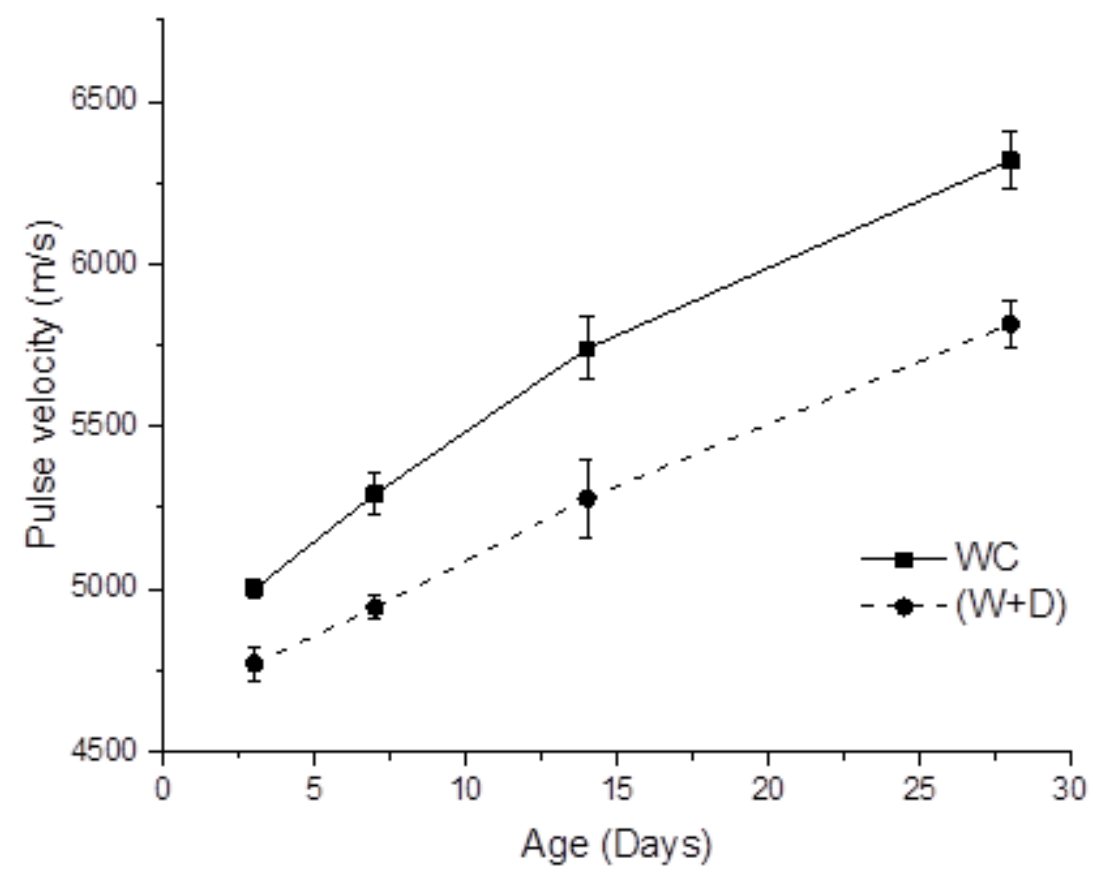

Figure 2: Pulse velocity readings of the mixes

At the early age of 3 days, the pulse velocity of the WC samples was about $250 \mathrm{~m} / \mathrm{s}$ higher than that of the $(\mathrm{W}+\mathrm{D})$ samples, but at later ages of 28 days, this difference became about $500 \mathrm{~m} / \mathrm{s}$. This seems 
to suggest that the quality of the concrete samples worsened or did not improve very much with time, when they were cured under the alternate wetting and drying curing condition as against when they were cured continuously under water.

\subsection{Compressive strength}

The compressive strength of the concrete cubes obtained at 3, 7, 14 and 28 days, are shown in Figure 3. From the figure, it can be seen that the compressive strength of the concrete samples cured continuously under water are higher than those cured by the alternate wetting and drying curing method, especially at the later ages. This correlates with the ultrasonic pulse velocity results shown in Figure 2, and shows the negative impact of the alternate wetting and drying curing method on the strength development of the concrete samples. Similar findings were also reported by (Mohr et al., 2005; Kampala et al., 2014).

Strength deterioration ratios (SDR) were computed for the concrete samples cured using the alternate wetting and drying curing method. SDR is defined as the ratio of the strength loss of the (W+D) samples relative to the strength of the samples cured continuously under water (WC) at the same age (Seleem et al., 2010). The computed SDRs are shown in Table 5. From the table, the SDR can be seen to increase with age. At the early age of 3 days, only a $12.98 \%$ reduction was observed in the strength of the $(\mathrm{W}+\mathrm{D})$ cured samples; but at the later age of 28 days, a higher percentage of $21.25 \%$ was observed. In a similar study by El-Ashkar et al. (2002), where the durability of pulp fiber-cement composites subjected to wet/dry cycling was investigated, it was observed that the average peak load was significantly reduced when the composites were subjected to the wet/dry cycling. The reason for this deterioration in strength can be attributed to the effect of thermal cracking. When high-strength concrete is allowed to dry prematurely, it can experience unequal tensile stresses that in an imperfectly hardened state cannot be resisted. This can result in the formation of thermal cracks, which is a common cause of deterioration in concrete structures that are exposed to environments where there are temperature changes as is the case of the $(\mathrm{W}+\mathrm{D})$ curing condition used in this study (Chai et al., 2012).

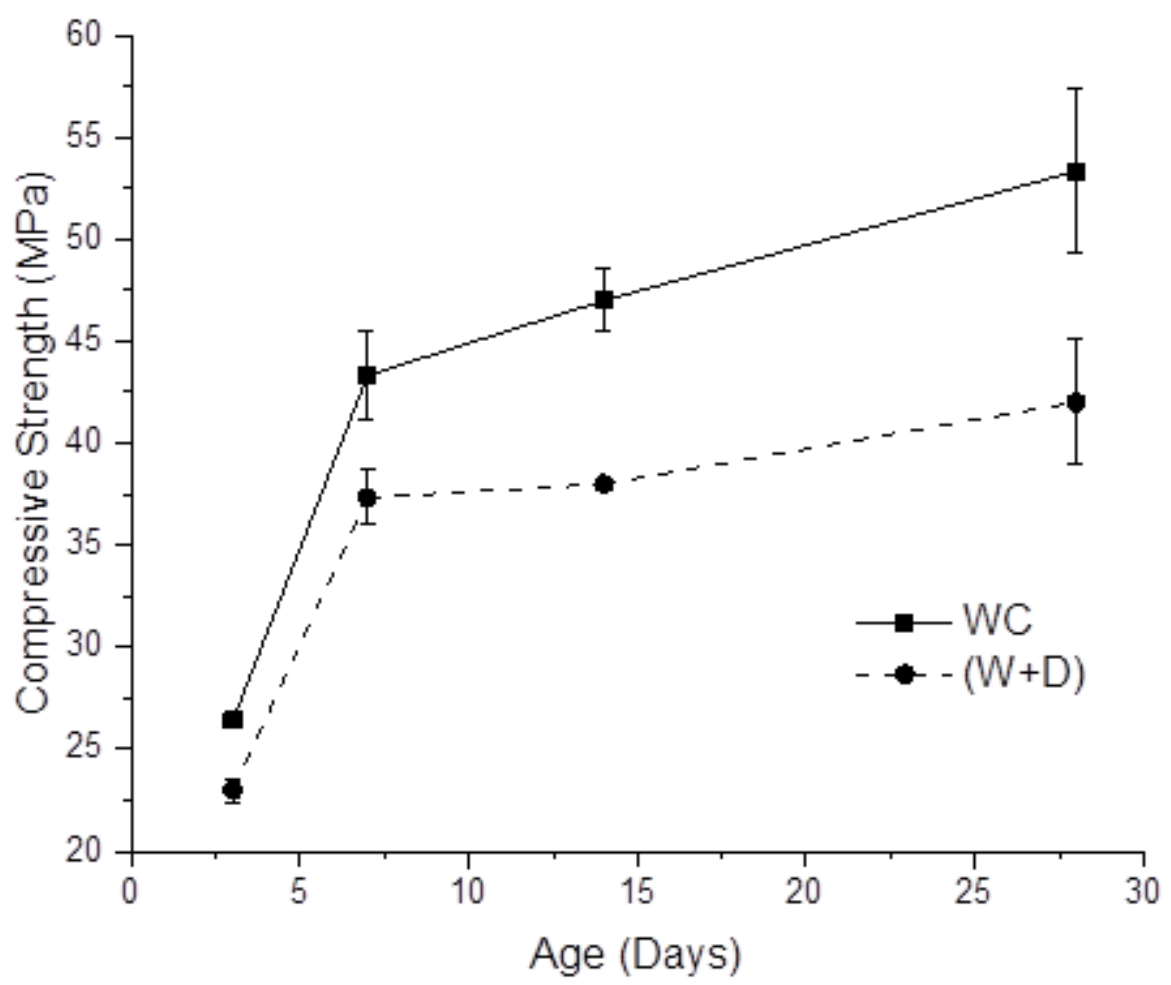

Figure 3: Compressive strength development of the mixes 
Table 5: Computed strength deterioration ratios (SDR) for (W+D) cured concrete samples

\begin{tabular}{cc}
\hline Age (days) & Strength deterioration ratio $(\%)$ \\
\hline 3 & 12.98 \\
7 & 13.85 \\
14 & 19.15 \\
28 & 21.25 \\
\hline
\end{tabular}

\subsection{Water ingress}

Table 6 and Figure 4 shows the percentage of water absorbed by the concrete samples after they had been cured in their respective curing regimes for 28 days, and immersed completely in water for 24 hrs. From the figure, it can be seen that the concrete samples that were subjected to the (W+D) curing regime, absorbed more water than those that were cured continuously under water. This implies that the pore structure of the $(\mathrm{W}+\mathrm{D})$ cured concrete samples was more porous than that of the WC cured concrete samples. This correlates with the UPV and compressive strength results shown in Figure 2 and 3 respectively.

Several studies (Rößler and Odler, 1985; Igarashi et al., 2004; Ogirigbo, 2016) have shown that there is a negative correlation between porosity and compressive strength. Hence, a concrete with a higher porosity will exhibit a low strength, and vice versa. The higher porosity of the (W+D) cured samples evidenced by the higher percentage of water absorbed by these same samples, can thus be said to be the reason for their low strengths.

Table 6: Weights of concrete samples before and after immersion in water

\begin{tabular}{llllll}
\hline $\begin{array}{l}\text { Curing } \\
\text { Method }\end{array}$ & Dry weight $\left(\mathrm{M}_{\mathrm{d}}\right)$ & Wet weight $\left(\mathrm{M}_{\mathrm{t}}\right)$ & $\begin{array}{l}\text { Water ingress }\left(\mathrm{W}_{\mathrm{a}}\right) \\
(\%)\end{array}$ & $\begin{array}{l}\text { Average water } \\
\text { ingress }(\%)\end{array}$ & $\begin{array}{l}\text { Standard } \\
\text { deviation }\end{array}$ \\
\hline \multirow{2}{*}{ WC } & 2.435 & 2.525 & 3.696 & & \\
& 2.535 & 2.635 & 3.900 & 3.663 & 0.26 \\
& 2.505 & 2.590 & 3.393 & & \\
$(\mathrm{~W}+\mathrm{D})$ & 2.430 & 2.630 & 8.230 & 5.652 & 2.45 \\
& 2.395 & 2.505 & 4.593 & & \\
\hline
\end{tabular}

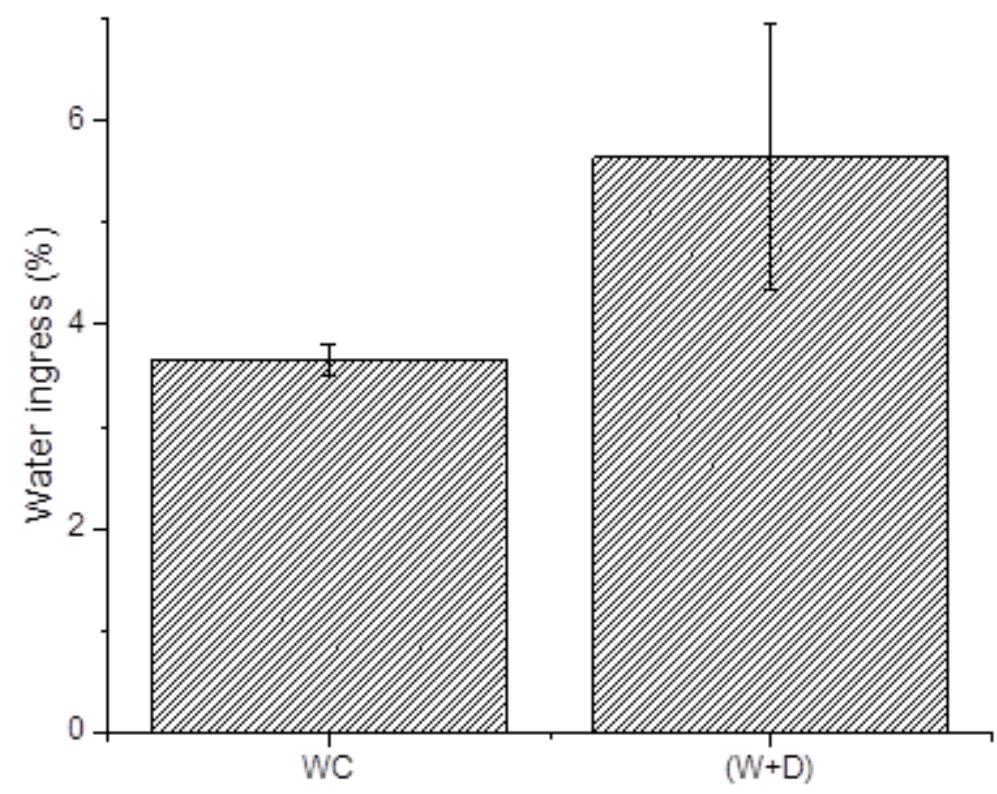

Figure 4: Percentage of water absorbed by concrete samples after 28 days of curing

\subsection{Depth of chloride penetration}

The results of the depth of chloride penetration obtained after 56 days of immersion of the concrete samples in the salt solution is shown in Figure 5. As was observed in the water ingress test result shown in Figure 4, the concrete samples that were cured by the alternating wetting and drying curing method recorded higher depths of chloride penetration than those that were cured continuously under water. The depth of chloride penetration for the $(\mathrm{W}+\mathrm{D})$ cured concrete samples was about $13 \mathrm{~mm}$, 
whereas that of the WC cured samples was about $5 \mathrm{~mm}$. This shows that concrete samples subjected to alternate wetting and drying are more susceptible to chloride penetration or ingress. This is to be expected, given that they will have higher porosities (as seen in the percentage of water absorbed in Figure 4) and thus will be less resistant to the penetration of the chloride ions. This altogether shows the deleterious impact of this method of curing on the durability of high strength concretes.

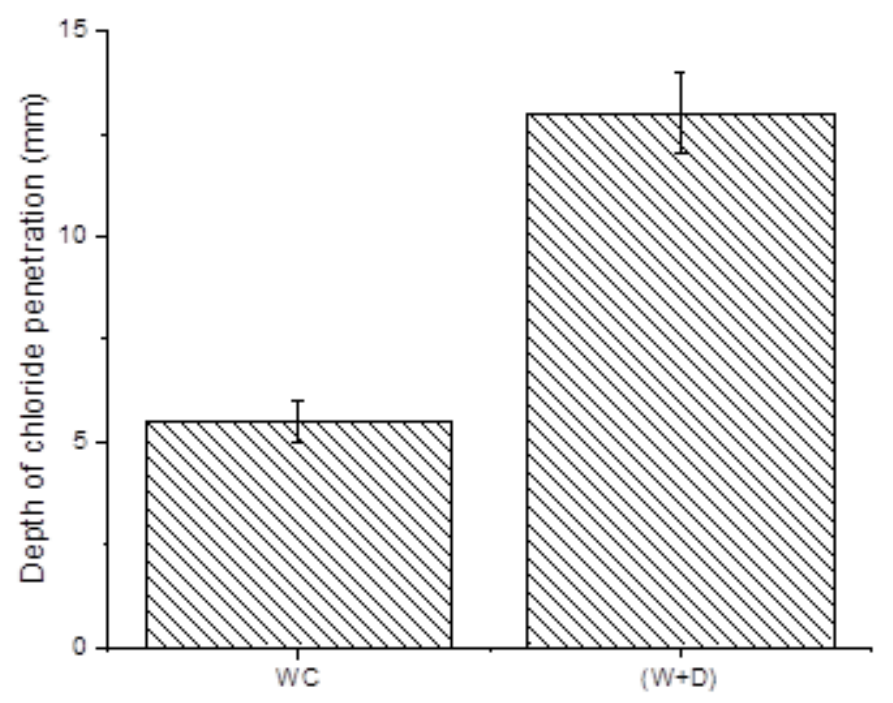

Figure 5: Depth of chloride penetration into concrete samples after immersion in salt solution for 28 days

\subsection{Conclusion}

This research focused on studying the effects of alternate wetting and drying method of curing on the strength and transport properties of high strength concrete. The results obtained from this study has shown that curing under alternate wetting and drying conditions can have adverse effect on the strength properties of high strength concrete, especially at the later ages. This is because of the effect of the premature drying of the concrete samples during the drying cycle, which can result in the formation of thermal cracks within the concrete. Pulse velocity measurements that were taken on the concrete samples indeed confirmed this, when higher pulse velocity readings were obtained for the concrete samples that were cured continuously under water as against those that were subjected to the alternate wetting and drying curing method. Similar observations were also made in the transport properties of the concrete which was studied via water and chloride ingress tests. The results of both tests generally showed that the pore structure of the concrete samples that were cured by the alternate wetting and drying curing method, were more susceptible to the penetration of water and chloride ions. It should be noted that other factors such as the duration of the wetting or drying cycle as well as the chloride concentration of the salt solution, can affect the properties of the concrete; however, these were not investigated in this study.

Overall, the results of this study implies that for coastal regions in tropical environments, the importance of ideal curing i.e. curing continuously under water, cannot be overemphasised, especially for high strength concretes. Since most concrete structures constructed in these areas are usually of high strength, it is therefore recommended that they are properly cured to ensure that they have good strength and transport properties.

\section{References}

BS1881-124:2011. Testing concrete: Methods for analysis of hardened concrete. BSI: London.

BS EN 12620:2002+A1. Aggregates for concrete. BSI: Brussels; 2008.

BS EN 196-1:2016. Methods of testing cement: Determination of strength. BSI: Brussels. 
Chai, G., van Staden, R., Guan, H. and Loo, Y. (2012). Impact of climate related changes in temperature on concrete pavement: a finite element study. In: 25th ARRB Conference Perth, Australia pp. 1-12.

El-Ashkar, N. H., Mohr, B., Nanko, H. and Kurtis, K. E. (2002). Durability of pulp fiber-cement composites to wet/dry cycling. In: Proceedings of the International Conference on Advances in Building Technology, 4-6 December 2002, Hong Kong, 1, pp. 233-237.

French, C. and_Mokhtarzadeh, A. (1993). High Strength Concrete: Effects of Materials, Curing and Test Procedures on Short Term Compressive Strength. PCI Journal, 38(3), pp. 76-78.

Garzon-Roca J., Sena-Cruz M., Fernandes P. and Xavier, J. (2015). Effect of Wet-Dry Cycles on the Bond Behaviour of Concrete Elements Strengthened with NSM CFRP Laminate Strips. Composite Structures, 132, pp. 331-340.

Güneyisi E. and Mermerdaş K. (2007). Comparative study on strength, sorptivity, and chloride ingress characteristics of air-cured and water-cured concretes modified with metakaolin. Materials and Structures, 40, pp. 1161-1171.

Hewlett P. C. (2004). Lea's chemistry of cement and concrete. 4th ed. Oxford: Elsevier ButterworthHeinmann.

Igarashi S., Kawamura M. and Watanabe A. (2004). Analysis of cement pastes and mortars by a combination of backscatter-based SEM image analysis and calculations based on the Powers model. Cement and Concrete Composites, 26, pp. 977-985.

Jaya, R. P., Bakar, B. H. A., Johari, M. A. M., Ibrahim, M. H. W., Hainin, M. R. and Jayanti, D. S. (2014). Strength and microstructure analysis of concrete containing rice husk ash under seawater attack by wetting and drying cycles. Advances in cement research, 26 (3), pp.145-154.

Kamran N. (2015). CM425-Concrete Technology. University of Washington, Winter Quarter. http//courses.washington.edu//cm425/aggregate.pdf. Accessed: 6/12/19, pp. 4.

Kampala, A., Horpibulsuk, S., Prongmanee, N. and Chinkulkijniwat, A. (2014). Influence of wet-dry cycles on compressive strength of calcium carbide residue-fly ash stabilized clay. Journal of Materials in Civil Engineering, 26 (4), pp. 633-643.

Mohr, B. J., Nanko, H. and Kurtis, K. E. (2005). Durability of kraft pulp fiber-cement composites to wet/dry cycling. Cement and Concrete Composites, 27 (4), pp. 435-448.

Neville A. M. (1996). Properties of concrete. 4th ed. New York: Wiley.

Ogirigbo, O. R. (2016). Influence of Slag Composition and Temperature on the Performance of Slag Blends in Chloride Environments. PhD Thesis, University of Leeds, UK.

Ogirigbo, O. R. and Inerhunwa, I. (2017). Strength and Durability Performance of Slag Blended Cements in High Temperature Environments. Nigerian Journal of Environmental Sciences and Technology (NIJEST), 1 (2), pp. 265-272.

Rößler M. and Odler I. (1985). Investigations on the relationship between porosity, structure and strength of hydrated portland cement pastes I. Effect of porosity. Cement and Concrete Research, 15, pp. 320-330.

Seleem, H. E. D. H., Rashad, A. M. and El-Sabbagh, B. A. (2010). Durability and strength evaluation of high-performance concrete in marine structures. Construction and building Materials, 24 (6), pp. 878-884. 
Sidney, F. (1979). Handbook of Concrete Engineering. 2nd edition, USA, ISBN 0-4442-2623-3, pp. 169-209.

Sobhan K., Gonzalez L. and Reddy V. (2016). Durability of a Pavement Foundation Made from Recycled Aggregate Concrete Subjected to Cyclic Wet-Dry Exposure and Fatigue Loading. Materials and Structures, 49, pp. 2271-2284.

Tang, J., Cheng, H., Zhang, Q., Chen, W. and Li, Q. (2018). Development of properties and microstructure of concrete with coral reef sand under sulphate attack and drying-wetting cycles. Construction and Building Materials, 165, pp. 647-654.

Cite this article as:

Durojaye O. M. and Ogirigbo O. R., 2020. Effect of Alternate Wetting and Drying on some Properties of High Strength Concrete in Tropical Coastal Environments. Nigerian Journal of Environmental Sciences and Technology, 4(1), pp. 172-181. https://doi.org/10.36263/nijest.2020.01.0189 